doi:

V.S. CHORNYI, S.L. SKRIPKA, O.Y. NECHYPORUK

Faculty of Radiophysics, Electronics, and Computer Systems,

Taras Shevchenko National University of Kyiv

(4g, Glushkova Ave., Kyiv 03680, Ukraine; e-mail: volodumur88@volia.ua)

\title{
FREQUENCY RESPONSE
}

OF SPLIT-RING RESONATORS AT DIFFERENT

PACS 81.05.Xj TYPES OF EXCITATIONS IN Ka-BAND

The frequency response of split-ring resonators (SRRs) at different types of excitations in the Ka-band has been investigated. The constructive parameters of SRRs are obtained from the electromagnetic simulation. Two unilateral and two bilateral samples of SRRs are experimentally investigated at the magnetic or electric excitation and a combination of both types of excitation. In order to get the widest resonance band, it is necessary to use a combination of magnetic and electric excitations. The resulting resonance width is $10 \mathrm{GHz}$. It is demonstrated that bilateral structures, despite the theoretical assumptions, may get a residual electric resonance. Since the depth of the resonance is less than $-6 \mathrm{~dB}$, it can be neglected, but the influence of combining two excitations must be taken into account.

Ke ywords: split-ring resonator, Ka-band, metamaterial, cross-polarization effect.

\section{Introduction}

Metamaterials are a bright example how a purely theoretical assumption [1] can evolve in a very promising technology, which finds applications to many fields of science and technology, in particular, to optics $[2,3]$ and microwave technique $[4,5]$. Some promising research directions are as follows: masking objects (to avoid the detection by radars) [6], plasma simulation [7], antenna design [8], overcoming the diffraction resolution limit in coventional optics $[9,10]$, various filters [11-13], etc. Among all variety of metamaterials were chosen $\mu$-negative structures, namely, SRRs. SRRs are common structures for the design of filters [11-13], creation of artificial environments, where negative values of effective magnetic susceptibility can be achieved [14], and substrates in antennas [8]. Their popularity is explained by a relative simplicity of design and the availability of materials that are used in their manufacture. Among the disadvantages are the lack of tunability, although several constructive solutions, which are based on SRR and have tunable properties, are known $[15,16]$.

The majority of works devoted to this topic in the microwave range deal with a narrow frequency band

(C) V.S. CHORNYI, S.L. SKRIPKA,

O.Y. NECHYPORUK, 2016 from 1 to $15 \mathrm{GHz}[4,6,11-13]$. The interest in this frequency subrange is explained by its prevalence and a relatively ease fabrication of samples. The typical size of a resonator can be estimated as $\lambda_{0} / 10$, where $\lambda_{0}$ is a resonance wavelength. The requirements of the manufacturing precision proportionally increase with decreasing the sample size. This imposes an additional restrictions on the material of the substrate, because the dispersive effects should not affect the measurement in a working frequency range. The Kaband $(26.5-40 \mathrm{GHz})$ was chosen. This range is begun to develop for the satellite communication. The losses in the atmosphere for this range are greater than for other widely used, but occupied bands. This range is also used in radiolocation at short distances.

The aims of this work are the calculation of parameters of SRRs, by using the electromagnetic simulation, and their experimental investigation at the magnetic or electric type of excitation and their combination.

\section{Split-Ring Resonators. The Calculation of Constructive Parameters}

SRRs were first proposed in [2]. A SRR consists of metallic split rings printed on a microwave dielectric circuit board. There are two types of excitation: magnetic and electric. When a resonator is ex-

ISSN 2071-0186. Ukr. J. Phys. 2016. Vol. 61, No. 1 

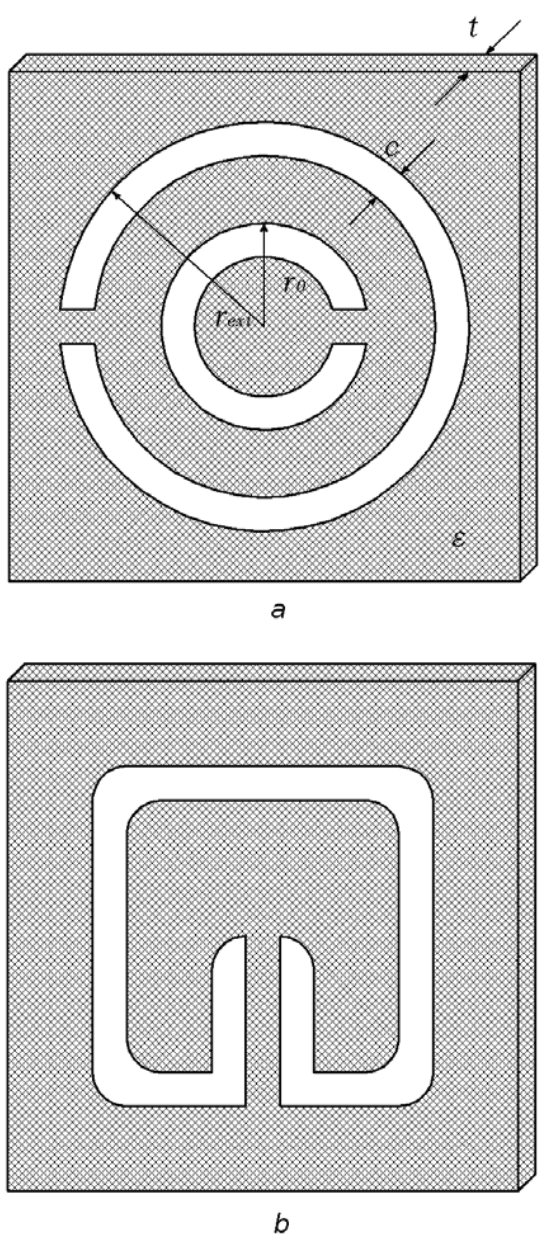

Fig. 1. Unilateral SRRs: EC-SRR (a); R-SRR (b). Metallizations are in white, and the dielectric substrate is hatched

cited by a time-dependent external magnetic field directed perpendicularly to the plane of rings, the cuts on each ring force the electric current to flow from one ring to another one across the slots between them, taking the form of a strong displacement current. Some types of SRRs can be excited by an electric field, which is located in the plane of cuts [5]. The motion of charges leads to the formation of an electric dipole in this case. The SRRs with inverse symmetry have no electric excitation $[5,17]$. The case where the SRR has two types of excitation is called the cross-polarization effect. This effect can be considered as negative, because the frequency response of the resonator will depend on its position relative to the electric field. But, in such a way, the frequency response can be con-

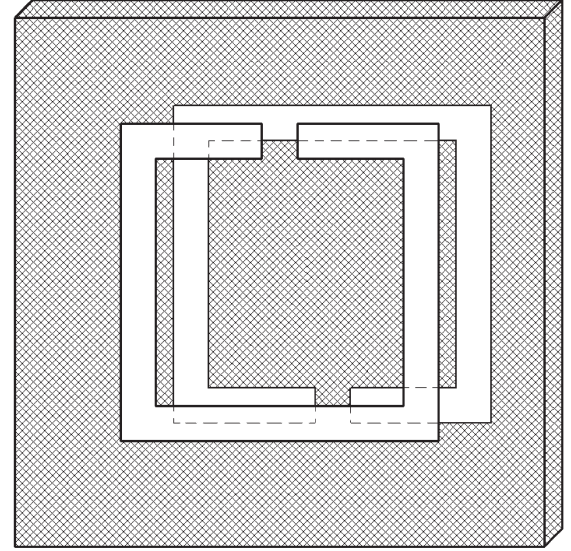

a

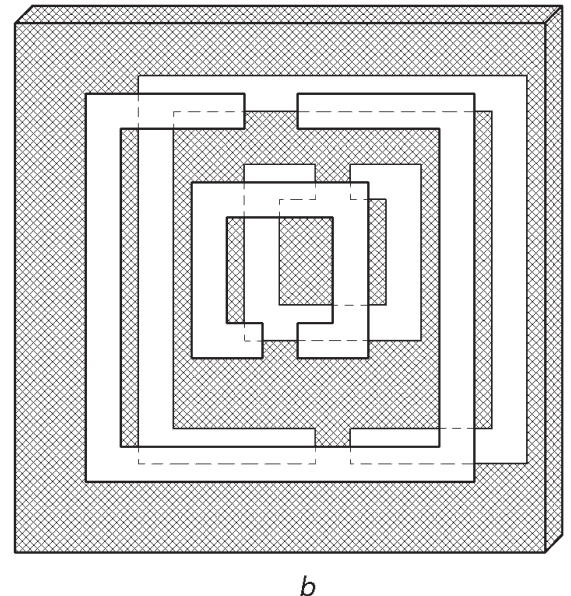

Fig. 2. Bilateral SRRs: BC-SRR (a); DB-SRR (b). Metallizations are in white, and the dielectric substrate is hatched

trolled in a small range (as compared to the tunable resonators).

There are many variations of SRRs [5, 18]. The following types of SRRs were chosen for the study: edge-coupled SRR (EC-SRR) (Fig. 1, a) [5], rectangular SRR (R-SRR) (Fig. 1, b) [6], broadside coupled SRR (BC-SRR) (Fig. 2, a) [17, 19], and double BCSRR (DB-SRR) (Fig. 2, b) [19]. The first two structures are unilateral, the last two are bilateral. The EC-SRR was proposed among the first ones, but now they have not lost their actuality [20]. The R-SRR is easiest to make as compared with EC-SRR, because it has fewer parts. The R-SRR were used in the creation of artificial media, in which it is possible to hide an object from radars [6]. Those structures have a cross-polarization effect. 


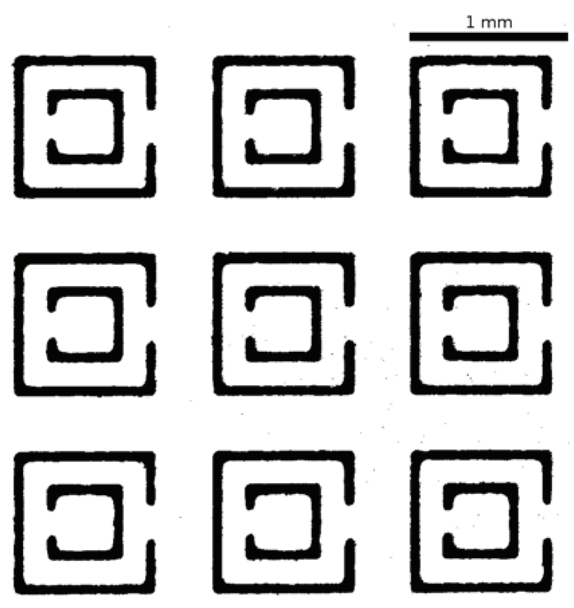

Fig. 3. Image of a part of DB-SRR

The BC-SRR [17] and DB-SRR [19] were proposed to avoid a cross-polarization effect. Those resonators consist of a dielectric substrate with metal strips on both sides. They do not possess a bianisotropy, because they have a mirror symmetry. In other words, the cuts in strips are located on opposite sides.

There are two different methods to determine the constructive parameters of SRRs: electromagnetic simulation and equivalent-circuit model. The main idea of the second method is that the resonator is replaced by an equivalent circuit, and the further calculations are carried out like the case of a conventional LC-circuit. The calculation of a resonance frequency within this method can be found in works [5, $21,22]$. The main advantage of this approach is a relatively simple calculation (with the use of any mathematical package including special Struve and Bessel functions). This calculation has no sufficient accuracy for the practical use in the Ka-band. Therefore, a lot of simplifications are made. Actually, the SRRs in the equivalent-circuit model is a system of resonant circuits. But, in such case, the calculation is quite difficult. However, in some cases, the accuracy may be quite acceptable, and this approach finds its application [5]. There is a risk that much of the resonance curve will be outside the working frequency band of measuring devices for the Ka-band. It is also possible to explore the behavior of the SRR at different types of excitation, namely the distribution of fields, currents, etc., by using the electromagnetic simulation. This method was chosen for the determination of constructive parameters of the resonators.
The software AWR Desing Environment 9.0.4847, package Microwave Office, was used in calculations. The electromagnetic simulation use Maxwell's equations for the determination of device characteristics, given its physical geometry. In addition, this method is free from restrictions of the equivalentcircuit model, because it uses a fundamental equations. However, the simulation time increases exponentially with the complexity of a structure. Therefore, it is important to minimize the complexity of the structure without loss of accuracy at the acceptable duration of a simulation. In the electromagnetic simulation, the Galerkin method in the spectral field was applied. The following design parameters were obtained for the EC-SRR: the external radius $r_{\text {ext }}=0.6 \mathrm{~mm}$, inner radius $r_{0}=0.3 \mathrm{~mm}$, width of rings $c=0.1 \mathrm{~mm}$, permittivity of the substrate $\epsilon=2.2$, thickness of the substrate $t=0.125 \mathrm{~mm}$, and cell size of $1.5 \times 1.5 \mathrm{~mm}$. As a result, we obtained the resonant frequency $f_{0}=32.2 \mathrm{GHz}$ and the bandwidth $\Delta f=2.44 \mathrm{GHz}$. More details of the calculation can be found in [23].

We used RT/duroid 5880 for dielectric substrate with the following parameters: permittivity $-2.2 \pm$ \pm 0.02 (at $10 \mathrm{GHz}$ ), loss-angle tangent - 0.0009 (at $10 \mathrm{GHz}$ ), and thickness $-125 \mu \mathrm{m}$. The thickness of the metallization is $17 \mu \mathrm{m}$. The size of each sample is $4.5 \times 4.5 \mathrm{~cm}$ (Fig. 3).

The production accuracy of samples is $\pm 25 \mu \mathrm{m}$. The dependence of the resonance frequency on specified deviations of the design parameters can be estimated using Microwave Office. The following results were obtained for R-SRR: the deviation of the width of one strip causes the deviation of the resonance frequency by $\pm 0.5 \mathrm{GHz}$; gap width $\pm 0.9 \mathrm{GHz}$. The following results were obtained for BC-SRR: strip width $- \pm 0.3 \mathrm{GHz}$; gap width $\pm 0.2 \mathrm{GHz}$; displacement of the rings relative to each other $- \pm 0.1 \mathrm{GHz}$. The absorption at the resonance frequency and the resonance width deviate by less than $1 \%$. However, it should be noted that, for the observation of these changes of the resonance frequency experimentally, we need to change the relevant design parameters simultaneously in all resonators in the structure. Therefore, an accidental variation in design parameters of SRRs in our experiments leads to a broadening of the resonance curve. But the devices based on SRR can be made on the basis of several resonators, so this factor must be considered. 


\section{Experimental Results and Discussion}

The experimental setup comprises fabricated samples, microwave generator with working frequency band 26-37 GHz, attenuation and SWR meter, ADC and $\mathrm{PC}$ for the signal visualization. Our samples were placed between two microwave horns to create a desired distribution of the electromagnetic field. For the excitation of samples, the TEM wave was used. The TEM wave was chosen, because the structures, which are based on SRRs, can be used to hide objects from the external probing radiation. However, the losses were about $12 \mathrm{~dB}$, which increases a measurement
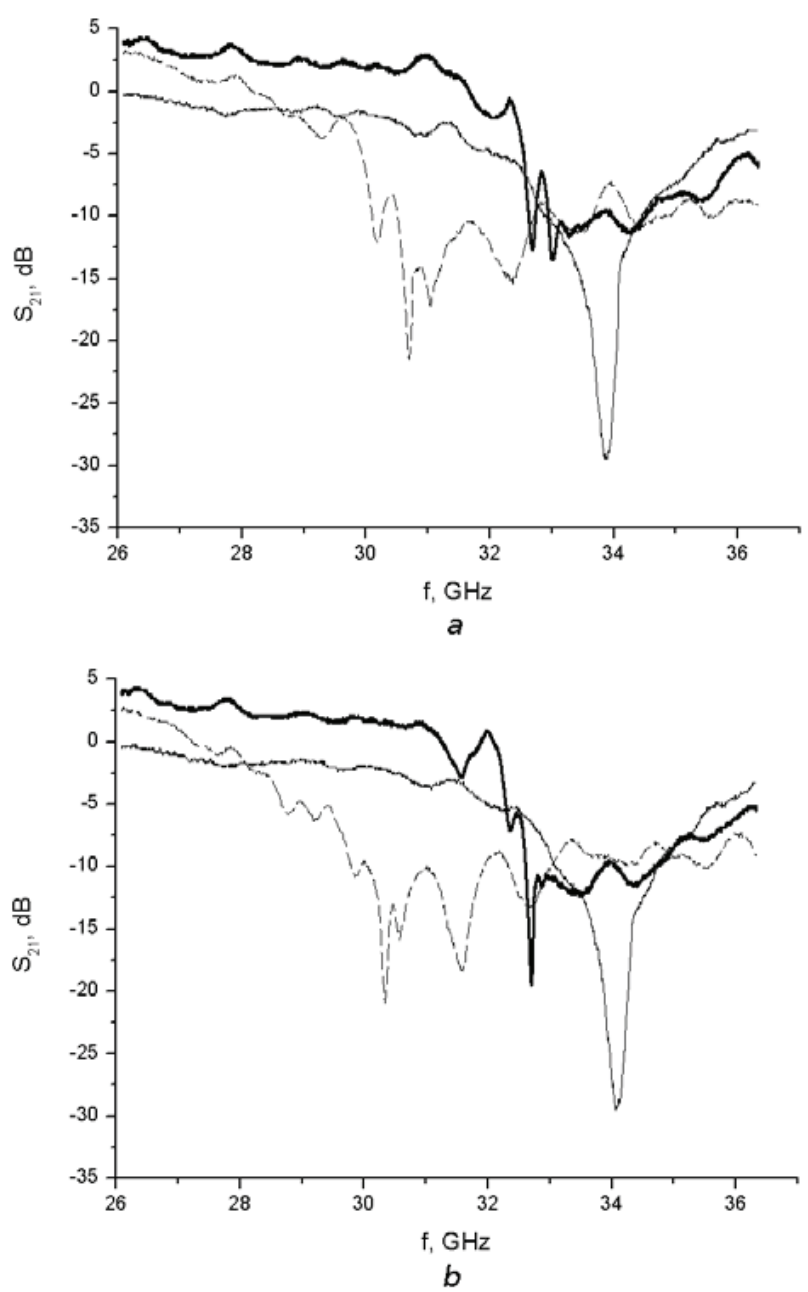

Fig. 4. Frequency response of unilateral SRRs: EC-SRR (a), R-SRR (b). Thick solid line for the magnetic excitation, thin solid line for the electric excitation, and dash line for their combination

ISSN 2071-0186. Ukr. J. Phys. 2016. Vol. 61, No. 1 error. The foam holder was made to fix the samples. The effect of the holder on measurements was taken into account by measuring the baseline without SRR.

The measurements were made for several positions of the structure, i.e. at different types of excitation. The magnetic excitation was obtained, when the magnetic field was perpendicular to the plane of the structure, and the electric field was parallel to the cuts in the rings (or strips). The magnetic and electric excitations were obtained, when the structure was turned by 90 degrees (without changing its spatial orientation). The electric excitation was obtained, when
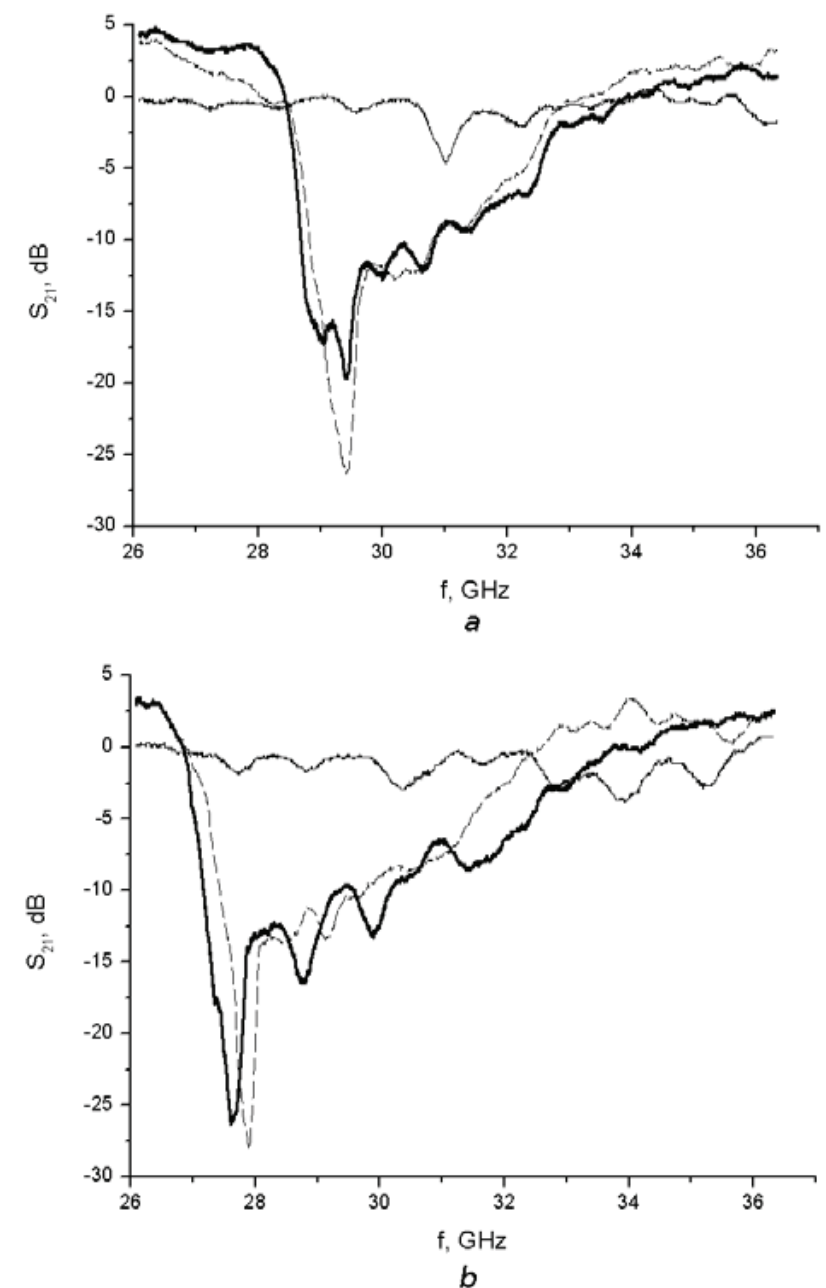

Fig. 5. Frequency response of bilateral SRRs: BC-SRR $(a)$, DB-SRR $(b)$. Thick solid line for the magnetic excitation, thin solid line for the electric excitation, and dash line for their combination 
the magnetic and electric fields were in the plane of $\mathrm{SRR}$, and the electric field was perpendicular to the direction of cuts.

The obtained frequency responses are presented at Figs. 4 and 5. The comparison of the results obtained by the electromagnetic simulation with experimental data is presented in Table 1.

It should be noted that the electromagnetic simulation gives a good results for the resonance frequency $f_{0}$ for unilateral structures and acceptable ones (especially compared to the equivalent-circuit model) for bilateral structures. Although the error for DB-SRR is comparable with others. This can be explained by the fact that this type of SRR is most difficult to manufacture, and the small errors in teh locations of strips that are opposite one another could lead to changes in the frequency of several $\mathrm{GHz}$, since the area of overlapping metallization layers is one of the main factors that determine the resonant frequency. The determination of the resonance width $\Delta f$, by using the elec-

Table 1. Comparison of results

obtained by the electromagnetic simulation (EM)

and experimentally (Exp) at the magnetic excitation

\begin{tabular}{|l|l|l|l|l|l|l|c|}
\hline \multirow{2}{*}{$\begin{array}{l}\text { SRR } \\
\text { type }\end{array}$} & \multicolumn{2}{|c|}{$f_{0}, \mathrm{GHz}$} & \multicolumn{2}{|c|}{$\Delta f, \mathrm{GHz}$} & \multicolumn{2}{|c|}{$L_{0}, \mathrm{~dB}$} & \multirow{2}{*}{$\begin{array}{c}\text { Error for } \\
f_{0}, \%\end{array}$} \\
\cline { 2 - 7 } & EM & Exp & EM & Exp & EM & Exp & \\
\hline EC & 32.2 & 33 & 2.44 & 5.63 & 20.73 & 19.52 & 2.4 \\
R & 31.7 & 32.7 & 0.97 & 6.7 & 13.38 & 13.49 & 3.05 \\
BC & 31 & 29.43 & 1.05 & 7.75 & 18.02 & 19.7 & 5.33 \\
DB & 31.2 & 27.6 & 1.42 & 7.61 & 18.16 & 28.31 & 13 \\
\hline
\end{tabular}

Table 2. Experimental results

\begin{tabular}{|c|c|l|c|l|}
\hline SRR type & Excitation type & $f_{0}, \mathrm{GHz}$ & $\Delta f, \mathrm{GHz}$ & $L_{0}, \mathrm{~dB}$ \\
\hline \multirow{2}{*}{ EC } & Mag. & 33 & 5.63 & 13.49 \\
& Elect. & 33.87 & 5.45 & 29.49 \\
& Mag. + Elect. & 30.7 & 8.89 & 21.63 \\
R & Mag. & 32.7 & 6.7 & 19.52 \\
& Elect. & 34.06 & 5.74 & 29.5 \\
& Mag. + Elect. & 30.34 & $>10$ & 20.95 \\
BC & Mag. & 29.43 & 7.75 & 19.7 \\
& Mag. + Elect. & 29.42 & 6 & 26.39 \\
DB & Mag. & 27.6 & 7.61 & 28.31 \\
& Mag. + Elect. & 27.9 & 8.83 & 28.29 \\
\hline
\end{tabular}

tromagnetic simulation, gives a too much error for using these data for the quantitative analysis. They can be used, with some caution, for the qualitative analysis. A good agreement was obtained for the level of absorption $L_{0}$ at the resonant frequency.

The experimental results for the resonance frequency and the width of the resonance band (at $3 \mathrm{~dB}$ ) are presented in Table 2. The artificial media, in which an object is hidden from outer radiation probe, require the resonators with the broadest resonance band. A combination of two types of excitation (magnetic and electric) is the best option for this purpose. The most promising in this regard is R-SRR, where the bandwidth is greater than $10 \mathrm{GHz}$. As was noted above, the resonance at the electric excitation in bilateral structures is absent, but the resonance curve at a combination of two types of excitation is noticeably different from the curve at the magnetic excitation. This fact should be considered when designing the devices based on this SRR.

\section{Conclusions}

In this paper, we have presented the frequency responses of four types of SRR at different types of excitation (magnetic, electric, and their combinations).

It is shown that, for the widest resonance band, it is the best to use such orientation of the structure, where both magnetic and electric excitations are present. This is because the frequencies for the magnetic and electric excitations are not equal. The broadening of resonance curves is obtained due to the interaction of two oscillations with different resonance frequencies. The difference between the resonance frequencies in the structures, where the cross-polarization effects are present is about $10 \%$. This feature is usually not taken into account at frequencies of several $\mathrm{GHz}$. The difference between the resonance frequencies of tens of $\mathrm{GHz}$ is already several $\mathrm{GHz}$.

We have demonstrated that the bilateral structures, despite the theoretical assumptions, may get a residual electric resonance. Since the depth of the resonance is less than $-6 \mathrm{~dB}$, it can be neglected, but the effect of a combination of two excitations must be taken into account.

1. V.G. Veselago, Sov. Phys. Usp. 10, 509 (1968).

2. J.B. Pendry, Phys. Rev. Lett. 85, 3966 (2000). 
3. G. Dolling, M. Wegener, C.M. Soukoulis, and S. Linden, Opt. Lett. 32, 53 (2007).

4. D.R. Smith, W.J. Padilla, D.C. Vier, S.C. Nemat-Nasser, and S. Schultz, Phys. Rev. Lett. 84, 4184 (2000).

5. R. Marqués, F. Martín, and M. Sorola, Metamaterials with Negative Parameters. Theory, Design, and Microwave Applications (Wiley-Interscience, New York, 2007).

6. D. Schurig, J.J. Mock, B.J. Justice, S.A. Cummer, J.B. Pendry, A.F. Starr, and D.R. Smith, Science 214, 977 (2006).

7. W. Rotman, IRE Trans. Ant. Prop. 10, 82 (1962).

8. J. Kim, C.S. Cho, and J.W. Lee, Electron. Lett. 42, 315 (2006).

9. A. Grbic and G. Eleftheriades, Phys. Rev. Lett. 92, 110401 (2004)

10. B.D.F. Casse, W.T. Lu, Y.J. Huang, E. Gultepe, L. Menon, and S. Sridhara, Phys. Rev. Lett. 96, 023114 (2010).

11. I. Gil, F. Martín, X. Rottenberg, and W. De Raedt, Electron. Lett. 43, 1153 (2007).

12. N.J. Mahdi, Mic. Opt. Tech. Lett. 53, 1961 (2011).

13. K.C. Yoon, J.H. Kim, and J.C. Lee, Mic. Opt. Tech. Lett. 53, 2174 (2011).

14. R.A. Shelby, D.R. Smith, and S. Schultz, Science 292, 77 (2001).

15. I. Gil, J. Bonache, J. García-García, and F. Martín, IEEE Trans. Microwave Theory Tech. 54, 2665 (2006).

16. K. Aydin and E. Ozbay, J. Appl. Phys. 101, 024911 (2006).

17. R. Marqués, F. Medina, R. Rafii-El-Idrissi, Phys. Rev. B 65, 144440 (2002).

18. L. Solymar and E. Shamonina Waves in Metamaterials (Oxford Univ. Press, Oxford, 2009).

19. E. Ekmekci and G. Turhan-Sayan, Prog. Electromag. Res. 12, 35 (2009).
20. H. Nornikman, O.T. Kean, A.B. Hisham, A.A.M.Z. Abidin, S.W. Yik, and O.M. Azlishah, Australian J. Basic Appl. Sci. 8, 262 (2014).

21. M. Shamonin, E. Shamonina, V. Kalinin, and L. Solymar, Microwave Opt. Tech. Lett. 44, 133 (2005).

22. J.D. Baena et al., IEEE Trans. Microwave Theory Tech. 53, 1451 (2005).

23. V. Chornyi, O. Nechyporuk, S. Skripka, and V. Danilov, Bulletin of T. Shevchenko Nat. Univ. Kyiv. Series Radioph. Electr. 19, 63 (2013).

Received 03.04.15

В.С. Чорний, С.Л. Скрипка, О.Ю. Нечипорук

ЧАСТОТНИЙ ВІДГУК ПОДВІЙНИХ

КІЛЬЦЕВИХ РЕЗОНАТОРІВ ПРИ РІЗНИХ

ТИПАХ ЗБУДЖЕННЯ В Ка-ДІАПАЗОНІ

$\mathrm{P}$ е $з$ ю м е

У даній роботі досліджено частотний відгук подвійних кільцевих резонаторів (ПКР) при різних типах збудження. Конструктивні параметри ПКР були отримані за допомогою електромагнітного моделювання. Два односторонні та два двосторонні зразки ПКР були експериментально досліджені при магнітному, електричному збудженнях та при їх комбінації. Було показано, що для отримання якнайширшої резонансної смуги потрібно використовувати комбінацію магнітного та електричного збуджень. Отримана ширина резонансу досягає 10 ГГц. Продемонстровано, що двосторонні структури, попри теоретичні припущення, мають залишковий електричний резонанс. Оскільки глибина резонансу менша за -6 дБ, то ним можна знехтувати, але потрібно враховувати вплив при комбінації двох збуджень. 